\title{
Os incensários portáteis braciformes no Egito antigo
}

\author{
Cássio de Araújo Duarte*
}

\begin{abstract}
DUARTE, C.A. Os incensários portáteis braciformes no Egito antigo. Revista do Museu de Arqueologia e Etnologia, São Paulo, 20:311-326, 2010.
\end{abstract}

Resumo: Recorrentes na iconografia do Reinado Novo, os incensários braciformes surgiram durante o Reinado Médio e, após o hiato do Segundo Periodo Intermediário, reapareceram investidos de uma simbologia solar que lhes conferiu uma nova aparência ao passo em que foram adotados para o culto nos grandes templos do Egito. A partir do estudo das fontes arqueológicas, pretendemos aqui compreender o contexto do aparecimento desse objeto, seu simbolismo e significância para a religião egipcia antiga.

Palavras-chave: Religião egipcia - Ritual - Incensários - Evolução de artefatos -Simbolismo.

É muito frequente vermos em cenas do Reinado Novo o rei ofertando incenso às divindades por meio de um artefato peculiar constituido de um antebraço com a mão espalmada portando um pequeno recipiente com diâmetro maior em sua parte superior temos sobre esse objeto não estão limitadas às imagens bidimensionais, e vários museus possuem em seu acervo exemplares de madeira, bronze ou outros metais que eram outrora utilizados para fins rituais, seja dentro dos santuários ou em cerimônias fúnebres privadas. ${ }^{1} \mathrm{O}$ receptáculo sobre a pequena mão

$\left.{ }^{*}\right)$ Doutor em Arqueologia pelo Museu de Arqueologia e Etnologia.<menkaura@terra.com.br>

(1) Por exemplo: British Museum BM 41606 (bronze), BM 67189 (bronze); Brooklyn 72.8 (bronze); Cairo JE 30700 (bronze); Louvre E 14687 (madeira), E 13531(bronze), E 11214 e E 11215 (somente as extremidades de prata); Pelizaeus 2367 (bronze); Museo Egizio di Firenze 12311 (bronze); Metropolitan Museum de New York 41.2.2 (bronze). espalmada corresponde às formas de um tradicional incensário imortalizado pelo hieróglifo R7 $\sqcup$, o qual inclui a coluna de fumo resultante da queima da preciosa resina. Outras versões desse simbolo podem ilustrar mais de uma coluna de fumaça, bolinhas de incenso ou variações na forma como a fumaça é

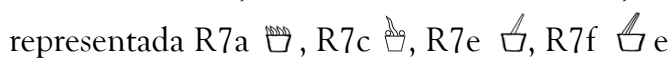
R7g b (Bonnamy e Sadek 2010: 903). Em algumas imagens, todavia, o recipiente nos incensários de braço pode assumir a forma de um vaso $n w 8$ (Caminos 1998: pr. 32; Leblanc e Siliotti 1997: 83, fig. 2; Siliotti 2006: 74; Weeks 2005: 359) ou pode ser mais aberto, como uma pequena cuia com borda (Figs. 1-3).

A representação do antebraço, por sua vez, corresponde ao hieróglifo D36 مـ utilizado como substituto aos símbolos D37

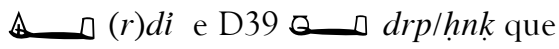
equivalem aos verbos "dar", "ofertar", "presentear" (Bonnamy e Sadek 2010: 820; Gardiner 1969: 454; Wilkinson 1996: 52-53). Desta 
maneira, o objeto ilustra, "hieroglificamente", $o$ ato de ofertar o incenso.

Com certa frequência, pouco antes do punho e como uma pulseira, esses instrumentos ritualisticos apresentam uma eflorescência de papiro $\nabla$. Sabemos que o símbolo do papiro M13 8 era muito utilizado em amuletos para significar o vigor da vida e o renascimento (Ferrari 1998: 59). É possivel que nessa categoria de incensários o símbolo do papiro evocasse a qualidade do incenso em trazer vitalidade por meio de uma força divina, uma vez que a palavra egípcia para a resina aromática, senetjer (sntrr) significa "tornar divino". Além disso, o significado da oferta, expresso pela forma do objeto, está associado à nutrição daquele que recebe a dádiva, que nada mais é do que uma doação da vida.

Outros elementos encontrados nesses artefatos são a presença de braceletes e, na parte central superior do braço, um recipiente para armazenar os grãos resinosos. Algumas vezes esse aparato assume a forma de um cartucho $\square^{2}$ e está acompanhado da imagem do rei agachado com as mãos sobre ele em atitude de oferta (Fig. 1).

$\mathrm{Na}$ outra extremidade do instrumento, aquela que ficava voltada para o ofertante, há uma cabeça de falcão com uma peruca tripartite 2 a qual, em alguns casos, aparece sobreposta por um disco solar ${ }^{3}$ De acordo com o contexto, e baseando-nos na circunstância de que quaisquer detalhes não são meramente decorativos, mas parte de sistema simbólico, é provável que esse arremate hieracocéfalo se atribua ao fato de que o olibano e outras substâncias que constituiam a fórmula do incenso fossem associados às lágrimas dos olhos divinos ou aos

(2) Como aquele da coleção do Metropolitan Museum de New York, $n^{\circ}$ 41.2.2, datado do Periodo Tardio.

(3) A representação do disco solar é mais presente nas ilustrações do que nos objetos propriamente ditos (p. ex.: British Museum BM 41606; Louvre E 11214), no entanto, em virtude da reutilização do metal e da quantidade reduzida de artefatos conhecidos dessa categoria, não é possivel extrairmos grandes conclusões a respeito dessa estatistica. olhos do deus propriamente dito (Goyon 1984: 84-85; 1997: 112, nt. 4, 113, 140; Moret 2007: $77-79,210) .{ }^{4}$ Em virtude da passagem mitica em que o deus-falcão presenteia seu pai Osíris com seu olho restaurado, o olho de Hórus tornou-se também um sinônimo para a oferenda (Wilkinson 1996: 42-43). Assim, a oferta do incenso significaria a própria doação do olho da divindade. ${ }^{5}$ No periodo helenístico-romano, os incensários de braço receberam o nome de "braço de Hórus" (Couton-Perche 2009: 252, $n^{\circ}$ 203), denominação que alude à passagem recém-citada e com clara conotação funerária por se associar às oferendas ao deus dos mortos. Neste caso, a cabeça divina na extremidade do instrumento funcionaria como o "sujeito" da oração que o artefato como um todo representa, a qual tem como verbo a palavra "ofertar", representada pelo braço, e como objeto, o incenso. O significado do instrumento assim codificado é reforçado de forma mais evidente naqueles objetos em que o rei aparece ajoelhado em atitude de oferta diante do reservatório da resina.

Por outro ponto de vista, além dessa construção de conceitos baseados em uma tradição textual, é possivel que o efeito sensivel da substância quando queimada, levantando colunas de fumaça aromática e sendo transpassada pelos escassos raios solares dentro do santuário possam ter contribuído para uma associação ainda mais intima entre o incensário e o deussol Rê' durante o culto divino diário, como sugerem aquelas representações em que o artefato apresenta um disco solar sobre a extremidade hierakocéfala - forma animal que também alude a essa manifestação divina.

Esse modelo de incensário não era o único utilizado a partir do Reinado Novo, mas as razões e contexto de sua origem carecem de interpretações. Antes de avançarmos sobre este assunto, e com o intento de compreendermos

(4) Em textos tardios, as gotas dessas resinas aromáticas também podiam ser associadas aos olhos dos deuses Atum, Osiris e de Seth.

(5) Várias divindades foram retratadas ofertando um olho wedjat, entre elas Thot (do qual trataremos adiante), Sekhemet e Nefertem (Wilkinson 1996: 43). 
os motivos de sua adoção e o imaginário religioso por detrás de sua concepção, faz-se necessária uma breve regressão aos periodos anteriores para que, desta maneira, possamos fazer uma avaliação mais consciente e fundamentada das fontes.

Durante o Reinado Antigo, os incensários que faziam parte do equipamento cultual portátil estavam limitados a três modelos. Um era um pequeno vaso $\square$ de onde derivou o hieróglifo R7 $\square$ - mencionado anteriormente e que pode apresentar algumas variações como os símbolos W10A $\square$ Aa4 $\square$ (Bonnamy e Sadek 2010: 859).

Outra variedade que vemos com grande frequência em cenas de mastabas (Figs. 4-6) (Badawy 1976: fig. 14), ${ }^{6}$ como nas capelas de Akhethetep (Ziegler 1993: 53, 106-107), Iteti (Badawy 1976: fig. 13) e Usernetjer (Murray 1905: pr. XXI), era constituída de duas partes, via-de-regra campaniformes, que se sobrepunham, uma servindo como recipiente para o incenso e a outra como tampa, e cada qual era arrematada por um prolongamento que servia, respectivamente, para o transporte e para a abertura da cobertura no momento da fumigação. Este modelo está expresso pelo hieróglifo R6 $\square$ - possivelmente o mesmo incensário da Fig. 4, apesar de este não aparecer acompanhado de tampa.

Outro aparato para o mesmo fim e de representação aparentemente restrita aos textos exibe uma forma alongada e corresponde ao hieróglifo R5 $\rightleftharpoons$ ?

No decorrer do Reinado Médio, não é incomum encontrarmos, além da primeira variedade citada, um tipo de altar portátil que reproduzia as formas de um papiro aberto $] \mathrm{e}$ que podia ser empregado para queima de

(6) A titulo de comparação com a cena da capela de Iteti, o autor ilustra quatro tipos de apresentação desse incensário nas cenas das mastabas de Giza de Ra'wer, Nefer, Niswkedw II, Kaninswt II, Imisetekai, Khnemwhetep, S 127/129, Sekhemka, Stikai, Kaiswdja, Inpwhetep, Nikawkhenemw, Wri e Khufuseneb.

(7) Por exemplo, em uma cena da mastaba de Usernetjer (Murray 1905: pr. XXI). incenso (Vandier 1964: 103, fig. 28). Um exemplo de seu uso pode ser observado na estela de Disuemib, pertencente à coleção do Museu do Louvre. ${ }^{8}$ Deste tipo de altar-incensário deriva uma variante que apresenta vários grãos de incenso empilhados sendo queimados sobre a bandeja $\bar{T}$, como mostra uma cena do ataúde de Djehutynakht (Terrace 1969: pr. VIII; Freed et al. 2009: 112).

É durante a transição da $11^{\mathrm{a}}$ para a $12^{\mathrm{a}}$ dinastia que surgem os primeiros indícios do uso de incensários portáteis à semelhança de um antebraço, embora não seja de nosso conhecimento a existência de quaisquer objetos reais dessa categoria em coleções privadas ou de museus. Temos, no entanto, representações desse instrumento ritual em maquetes e pinturas murais que expressam sua contextualização funerária. Duas maquetes pertencentes ao Metropolitan Museum de Nova York e ao Museum of Fine Arts, em Boston, destacam o artefato na mão direita de um sacerdote, o qual é o primeiro personagem de uma procissão fúnebre e que leva, sobre o ombro esquerdo, um avultado vaso hes (Figs. 7 e 8). Ambos os objetos, o recipiente portador de água e o incensário, se complementam em sua função de purificação no ritual funerário e precedem, tanto por sua natureza imaculada quanto por simbolicamente "limparem" o trajeto até a sepultura, os demais apetrechos levados ao falecido pelos outros personagens do cortejo.

O modelo encontrado no túmulo de Meketre (Fig. 7) ${ }^{9}$ (Winlock 1955: 39, 41-43, pr. 12), em Sheikh Abd el-Qurna, embora não seja explícito na representação das formas do incensário, se aproxima das linhas do braço estendido visto em outras imagens: ele começa alargado e gradativamente se afina no local onde deveria estar presente a mão, que foi substituida por um volume trapezoidal com a forma de uma mão cerrada. Apesar da rusticidade do objeto, a anatomia de um braço é bem sinalizada por sua região superior mais aplaina-

(8) Louvre C149 - N298 (Étienne 2009: 230-231).

(9) Chanceler sob os reinados de Mentuhotep II e III. MMA 20.3.8. 
da e pela semelhança do bloco que constitui o punho com a mão no incensário da outra maquete, pertencente a Djehutynakht (Freed et al. 2009: 152-154) (Figs. 8 e 9), ${ }^{10}$ que é primorosamente esculpida a despeito de suas pequenas dimensões. Se o primeiro exibe uma caixinha porta-incenso na parte superior média do braço, este já a incorpora pouco antes da mão, como se o recipiente e o braço fossem uma coisa única. O punho fechado e orientado para cima segura uma alça atrelada a um recipiente circular raso que conteria a brasa onde os grãos de incenso seriam queimados, caso o objeto em questão não constituísse um delicado modelo. No caso do incensário da maquete de Meketre, o mesmo receptáculo afeiçoa-se a uma pequena colher unida ao "punho", sem a elegância da alça vista na maquete de Djehutynakht, onde até minúsculas unhas estão indicadas nas extremidades dos dedos.

As pinturas das capelas funerárias, como no caso das tumbas de Beni Hassan (Figs. 1014), ${ }^{11}$ fornecem um testemunho ligeiramente diferente em relação às formas dos incensários das maquetes. Ao invés de um punho contendo à frente o receptáculo com a brasa luminescente, esses incensários ilustram a mão espalmada portando uma pequena cuia dentro da qual a preciosa resina é, via-de-regra, ilustrada sendo depositada sobre a chama (Figs. 10, 11). Quanto ao restante das características, com exceção a ligeiras mudanças como o comprimento do instrumento, acabamento ou o estilo do compartimento de estocagem do incenso, estruturalmente o objeto tem suas formas inalteradas.

Em nenhum dos casos citados, seja nas maquetes ou nos afrescos, o incensário braciforme do Reinado Médio apresenta na extremidade próxima ao seu portador um acabamento minimamente semelhante à cabeça de um falcão. Se não são arrematados com um fim abrupto (Figs. 7, 13-14) - um detalhe pouco

(10) Datada do final da $11^{\text {a }}$ dinastia e início da $12^{\text {a }}$ Boston, MFA 20.1124.

(11) Sepultura de Amenemhat, tumba $n^{\circ} 2$ (Newberry 1893: prs. XVII, XVIII; 1900: pr. XVII) e também na tumba n³ (Newberry 1893: pr. XXXV). caro à estética egípcia -, estes são concluidos com as elegantes linhas de uma eflorescência de papiro aberta (Figs. 8-12).

É interessante observar que esse objeto inovador por suas formas não tenha sido adotado de pronto na iconografia da realeza, a julgar pelos registros da Capela Branca de Senwsret I (12a dinastia), onde o rei aparece segurando o pouco prático incensário em forma de vaso. Embora sejam raras as cenas sobreviventes de monumentos reais do Reinado Médio, e esta circunstância limite uma percepção mais precisa, ainda assim é intrigante que o monumento desse rei não tenha espelhado uma mudança que, hipoteticamente poderia ter surgido nos segmentos mais seletos da elite governante. ${ }^{12}$ Se acreditarmos na versão das fontes disponiveis, o incensário braciforme surgiu na mesma região de onde emergiu a classe dominante da época, o Alto Egito. Se for correta, esta constatação torna ainda mais intrigante que esse utensílio com aplicação tão prática e simbolismo explícito não tenha sido adotado desde o principio pela realeza em sua iconografia ou ter sido em seu seio concebido.

As pinturas e a matéria-prima das maquetes sugerem que esses artefatos eram originalmente feitos de madeira (Fig. 10), ${ }^{13}$ um material acessivel e que pode indicar as origens modestas do instrumento religioso. Mas, ainda assim, por que esse objeto surgiu? Quais motivações fizeram com que os diversos tipos de incensários existentes não fossem suficientes para que um novo modelo fosse introduzido? O contexto de seu uso poderia trazer alguma luz ao propósito de sua criação?

Em virtude de nossas fontes serem de caráter eminentemente funerário - como sublinham as maquetes de Nova York e Boston - é de se acreditar que o emprego do incensário de braço tenha surgido para esta finalidade, e somente a partir do Reinado Novo o uso do

(12) A capela de calcita de Amenhotep I, da 18 a dinastia e igualmente em Karnak, apresenta uma cena do rei fazendo uso do mesmo incensário arcaico.

(13) Pelo menos é o que sugerem as imagens no túmulo de Amenemhat (Newberry 1893: prs. XVII, XVIII; 1900: pr. XVII). 
artefato teria sido estendido para uso litúrgico. Embora o aspecto simbólico da oferta seja vital em sua concepção, um motivo bastante relevante sugere o porquê de sua criação: a mobilidade.

Analisando as condições físicas do Alto Egito e contrastando-as com os contextos do emprego do incensário braciforme nessa região, percebemos que esse modelo é mais prático em seu manuseio que os modelos tradicionais por evitar queimaduras em seus portadores enquanto andam pelo terreno desértico altamente acidentado quando se dirigem para as sepulturas. A praticidade é igualmente notável durante o ritual de abertura da boca, quando o sacerdote estende a fumigação do incenso até o rosto da múmia ou do ataúde depositados em pé diante do túmulo, como ilustra uma cena do livro dos mortos de Hunefer ${ }^{14}$ (Fig. 15). Não deve ser por acaso que o aparecimento dessa categoria de artefato religioso coincide com uma profunda mudança na religião funerária que se operou durante o $1^{\circ}$ Periodo Intermediário e o Reinado Médio, quando o antigo tratamento dispensado à mumificação foi substituido pela prática de deixar o corpo inteiramente contido por bandagens e adornado com uma máscara funerária, tal como a própria múmia do deus Osíris. Esse método possibilitou deixar o defunto em pé diante da sepultura (Hayes 1959: 31, fig. 14; Quirke e Spencer 1997 149, fig. 113) para as cerimônias fúnebres antes de encerrá-lo definitivamente em seu sarcófago. Com um incensário convencional na forma de um pequeno vaso, a aproximação do fumo à face do defunto durante o ritual era certamente mais dificil, especialmente se entre a múmia e o sacerdote houvesse uma mesa de oferendas, e podia propiciar acidentes com as brasas que libertavam o perfume da resina. ${ }^{15} \mathrm{E}$ se realizado juntamente com a libação, a coordenação do

(14) Museu Britânico, nº 852,0525.1.5.

(15) Na capela vermelha de Hatshepsut, vemos a rainha portando o incensário de braço especialmente quando ela se encontra distante das imagens divinas ou quando estas estão em um patamar mais elevado (cf. Burgos e Larché 2006: 46-47, 49, 52, 111). movimento de ambos os braços teria tornado ainda mais desafiadora a execução da tarefa sem que eventualmente não tenha ocorrido esse tipo de circunstância.

No que concerne ao simbolismo, como já tivemos a oportunidade de comentar, o objeto é explicito ao reproduzir as formas do hieróglifo correspondente aos verbos "ofertar", "dar" e "presentear". Desta maneira, o braço do sacerdote era, por meio do objeto sacro, "estendido" até o morto sem que o significado do ato da purificação fosse perdido. Na verdade, como veremos, o ato foi re-significado por esse artefato.

Olhando a questão por outro prisma, até onde sabemos, os templos antes do Reinado Novo não ostentavam grandes dimensões que requeressem praticidade na mobilidade de um incensário, e essa condição pode ter inibido grandes transformações em suas formas. Foram as transformações culturais na transição entre Reinado Antigo e o Médio, no seio da religião funerária no Alto Egito e a geografia desse território que estimularam o surgimento do incensário braciforme e lhe deram popularidade. E se por um lado aparecia o novo modelo de defumador, por outro, aquele composto de duas partes caiu em desuso após o Reinado Antigo.

Durante o Reinado Novo, permanece o modelo de incensário de braço com a palma da mão estendida portando o recipiente. A julgar pelas cenas em templos e sepulturas, que testemunham a adoção do artefato pela realeza e pela elite sacerdotal, a caixinha que armazenava os grãos da resina foi substituída por um pequeno receptáculo que, em artefatos de metal era fundida (Fig. 16) com o resto do objeto em uma só peça e podia exibir as formas de um cartucho comentadas mais acima. Esse simbolo que encerra o nome real não deve seu emprego nos incensários à elegância de suas formas para o simples armazenamento de incenso, mas está simbolicamente relacionado ao uso da palavra durante os rituais. Assmann (2009: 114) lembra o uso dessa resina juntamente com as "litanias de apelação", que são invocações de uma divindade em todos os seus nomes. Desta maneira, à medida que cada grão da substância 
era depositado sobre as brasas, uma apelação da potência divina era recitada.

Mas a alteração mais significativa se deu na extremidade oposta àquela onde o incenso era queimado. Lá, o acabamento em forma de flor de papiro deu lugar à representação da cabeça de falcão com a peruca tripartite sobre a qual podia estar ilustrado um disco solar (Figs. 1-3, 17). ${ }^{16}$

Devido ao simbolismo que esse instrumento de culto passou a encerrar, e do qual tratamos de início, é difícil acreditar que essa alteração tenha sido fruto meramente do gosto estético. Se uma revolução na religião funerária trouxe ao Reinado Médio a criação do incensário de braço, é de se acreditar que outra transformação no imaginário religioso o tenha modificado. E tamanha foi a mudança, que um instrumento antes restrito ao uso funerário foi adotado pelo rei (Figs. 1-2) e pela alta classe sacerdotal (Fig. 3) e passou a ser principalmente produzido em metal (Fig. 16) para uso em importantes templos do Estado. Embora o uso do artefato não tenha banido outras formas de incensário, que continuaram presentes nas cenas ritualisticas lado a lado com o novo modelo, é durante o Reinado Novo que surge o hieróglifo que capta as linhas antropomorfizadas desse instrumento ritualistico, mas já com sua terminação hierakocéfala, tal como atestam as inscrições do ritual do culto divino diário no templo erigido por Seti I, em Ábidos. A integração desse modelo de incensário ao repertório de signos hieroglificos atesta a magnitude que o artefato atingiu nessa época. Na versão transmitida por Moret (2007: 235), contudo, ao invés do arremate alusivo a um falcão consta no hieróglifo do incensário de braço uma inédita terminação leontocéfala sobreposta por um disco solar. Entretanto, trata-se de uma interpretação equivocada do símbolo como ilustra a mais recente publicação do templo por A. Calverley e M. Broome (1935, pr. 5), onde o hieróglifo presente no

(16) Em virtude da escassez de objetos antigos, possivelmente para reutilização do metal, os incensários braciformes produzidos em bronze datam dos periodos Tardio ou Ptolemaico e estes não apresentam o símbolo solar. mesmo texto ${ }^{17}$ indica sua referência ao deus falcão e consta como um determinativo da palavra shtp, que significa "incensário de braço" (Bonnamy e Sadek 2010: 572; Faulkner 1996: 239; Hannig 2006: 797). ${ }^{18}$

Ainda que, grosso modo, prevaleçam as imagens de reis e sacerdotes utilizando esse objeto ritual, não é raro encontrarmos cenas de indivíduos comuns realizando eles próprios os ritos, talvez com um instrumento de valor mais modesto que os de bronze ou outros metais utilizados nos templos. Contudo, conhecemos uma cena no já citado templo de Ábidos que ilustra Thot portando um incensário braciforme em sua mão esquerda - que se encontra abaixada - enquanto a direita está elevada em direção a Ramsés II (Fig. 17). Essa representação não implica necessariamente que quaisquer deuses estivessem incumbidos de tal tarefa, e é provável que a natureza de Thot enquanto "sacerdote e escriba" o habilita para a função. Por outro lado, encontramos durante o Periodo Tardio outras representações desse deus, seja como babuíno ${ }^{19}$ ou antropomórfico e ibiocéfalo, ${ }^{20}$ portando um olho wedjat ${ }^{21}$ (Fig. 18), em uma possivel referência ao "mito da deusa longínqua” (Desroches-Noblecourt 1997; InconnuBoucquillon 2001; Kaper 2003: 72). Essas imagens nos lembram a atitude explicitada pelo incensário de braço ao oferecer as "lágrimas" resinosas de olibano ou mirra que são associa-

(17) "Fazer o incensamento quando se descobre a face apresentando (lit. com) o incensário": "Faire l'encensement quand on découvre la face en présentant (litt. avec) l'encensoir" (Moret 2007: p. 235).

(18) A palavra deriva do verbo shtp, que significa apaziguar, satisfazer, pacificar, porvir.

(19) Por exemplo, Brooklyn Museum 08.480.80; British Museum BM 64599, Metropolitan Museum de New York 44.4.41; Musées Royaux d'Art et Histoire, Bruxelas E.2378; Walters Art Gallery 48.475 e 48.1543.

(20) British Museum BM 60481; Louvre E 3803 e N 4490; Museum of Fine Arts, Boston 72.2720.

(21) Nas dez imagens que são de nosso conhecimento, sete ilustram o olho direito (British Museum BM 64599; Brooklyn Museum 08.480.80; Louvre N 4490; Metropolitan Museum de New York 44.4.41; Museum of Fine Arts, Boston 72.2720; Walters Art Gallery 48.475, 48.1543) associado ao sol - e as outras três (British Museum BM 60481, Louvre E 3803, Musées Royaux d'Art et Histoire, Bruxelas E.2378), o olho esquerdo, correspondente à lua. 
das ao olho de Hórus ${ }^{22}$ ou de Rê‘. Além disso, no mito Thot vai ao encontro da deusa para "apaziguar" (shtp) sua fúria leonina (Cortegianni 2007: 299 ; Inconnu-Boucquillon 2001) - o verbo utilizado é o mesmo que deu origem para a apelação do incensário de braço (shtpy). Vemos assim uma grande similaridade simbólica entre essa categoria de instrumento ritual e a atitude de Thot nas representações tardias que sugerem a partilha de um conceito comum por ambos e que os vincula à temática solar. Somado a esse simbolismo, shtp é uma expressão empregada para denominar o sol poente (Assmann 2009: 114).

Faz-se necessária uma pesquisa mais ampla para sabermos a partir de qual reinado o incensário braciforme foi introduzido na iconografia da realeza durante o Reinado Novo, mas sabemos que já estava presente na época de Hatshepsut, como confirmam as cenas da capela vermelha de Karnak (Burgos e Larché 2006: 46-47, 49, 52, 111). Em virtude do elemento hieracocéfalo desses artefatos, é de se acreditar que se objetivava estabelecer uma relação direta entre o objeto e os deuses Rê‘ e Hórus, vínculo este motivado pela crescente solarização da religião egipcia durante o periodo (Müller 2001: 124-125). Além do conteúdo mitológico implícito na oferta do incenso enquanto "olho divino", o efeito da queima da resina salientava os escassos fachos de luz que penetravam no interior dos santuários dando a eles tridimensionalidade e substância, enquanto, por outro lado, lhes conferia o forte perfume da matéria sagrada derretida, criando um ambiente cênico de profundo mistério ao ritual de culto diário.

Vale ainda outra observação. Alguns relevos datados do reinado de Amenhotep IV/ Akhenaton - rei que se notabilizou por sua politica de negação de outras divindades que o deus sol Aton - ilustram o rei ou um sacerdote empregando o alongado objeto em rituais seja diante da divindade solar - no caso da repre- sentação do rei ${ }^{23}$ - ou diante do trono portátil do soberano (Reeves 1999: 89). Assim, e em conformidade com o contexto politico-religioso da época, é plausivel supormos que o incensário de braço com sua representação falconiforme não tenha sido vinculado, até o período, a outro deus que o próprio Rê‘, apesar das associações que a documentação posterior estabelece com Osíris e Seth, por exemplo. Esses desdobramentos simbólicos são, possivelmente, fruto das formulações teológicas do Terceiro Período Intermediário em diante. A associação intima entre o artefato e o deus Rế encontra respaldo em diversas imagens a partir do reinado de Akhenaton e Tutankhamun (Figs. 1 a 3 e 19) nas quais o arremate hieracocéfalo do incensário apresenta um disco solar sobre ele, como atestam os relevos do templo de Luxor (Epigraphic Survey 1994: prs. 5, 9, 10, 55, 56, 60, 61, 78, 82, 85, 105, 107; 1998: prs. 132, 158, 161, 167; Robins 1997: 159, fig. 187; Davies 1905, prs. V, VIII) e cenas do periodo raméssida. É possivel que esse artefato já possuisse um simbolismo solar nos reinados anteriores ao de Akhenaton, mas é digno de nota observar que foi durante seu reinado- se nossas informações estiverem corretas - que a imagem do disco solar foi associada à representação do incensário braciforme, como se este fosse uma metáfora das próprias imagens de Aton com seus múltiplos braços estendidos ofertando simbolos da vida.

Uma vez amplamente adotado pelos templos do país ou em cerimoniais fúnebres privados, o incensário braciforme manteve seu prestigio nos rituais diários destacando-se como um elemento canalizador das forças divinas em favor da manutenção da ordem $\left(m 3^{\top} t\right)$ cósmica. Seu uso, todavia, não levou ao abandono de formas mais tradicionais de incensários, com exceção do modelo composto de duas partes simbolizado pelo hieróglifo R6, aparentemente substituído pelo tipo que aqui estudamos. Esta circunstância prova a ambivalência e riqueza da cultura egipcia em manter elementos da tradição e, ao mesmo tempo, opor-se ao engessamento de uma norma rígida.

(23) Louvre 13482ter (Étienne 1999: 207, n²1; Redford 1999: 56).
(22) Uma cena parecida, mas associada à proteção e cura do olho de Sokar, aparece nas primeiras versões do Livro do Amduat (Hornung e Abt 2007: 111, 126). 


\section{Conclusão}

Tivemos a oportunidade de expor sucintamente o desenvolvimento do incensário de braço durante o periodo faraônico e tecer algumas conjecturas acerca do contexto de sua origem e da riqueza simbólica a ele vinculada. Tendo surgido após a cristalização de novas práticas funerárias que conferiam à múmia a capacidade de ser posta em pé diante do túmulo por ocasião da cerimônia da abertura da boca, e em meio ao cenário rochoso do Alto Egito, o incensário portátil à semelhança de um antebraço em atitude de oferta tornou-se um instrumento preferido pela praticidade em sua manipulação e por estender simbolicamente as dimensões físicas do braço do sacerdote oficiante nos rituais funerários. Até onde nos foi possivel chegar, em virtude da escassez de fontes da época, tudo indica que foi o contexto funerário do Reinado Médio que possibilitou e inspirou a origem desse objeto sacro, o qual era utilizado em cerimoniais privados e ainda não havia sido adotado pela realeza. Foi somente a partir do Reinado Novo, pelo menos a partir de Hatshepsut, que o artefato foi incorporado aos rituais oficiais dos grandes templos e quando, presumivelmente, ganhou notas de maior nobreza por passar a ser produzido em metal. Além disso, assumiu uma nova apresentação estética que incorporou à antiga forma de um braço ofertante uma simbologia solar particular, conferindo assim uma carga sobrenatural e mitica ao drama ritualístico diário.

DUARTE, C.A. Arm-shaped censers in ancient Egypt. Revista do Museu de Arqueologia e Etnologia, São Paulo, 20:311-326, 2010.

Abstract: Recurrent among the New Kingdom iconography the arm-shaped censers appeared during the Middle Kingdom and, after the hiatus of the Second Intermediate Period, reappeared modeled by a solar symbology what gave them a new shape while they were adopted for daily cult on Egyptian temples. Based on the study of archaeological sources I propose to understand the context of the arm-shaped censers emergence, its symbolism and meaning for the ancient Egyptian Religion.

Keywords: Egyptian religion - Ritual - Censers - Artifact evolution Symbolism. 


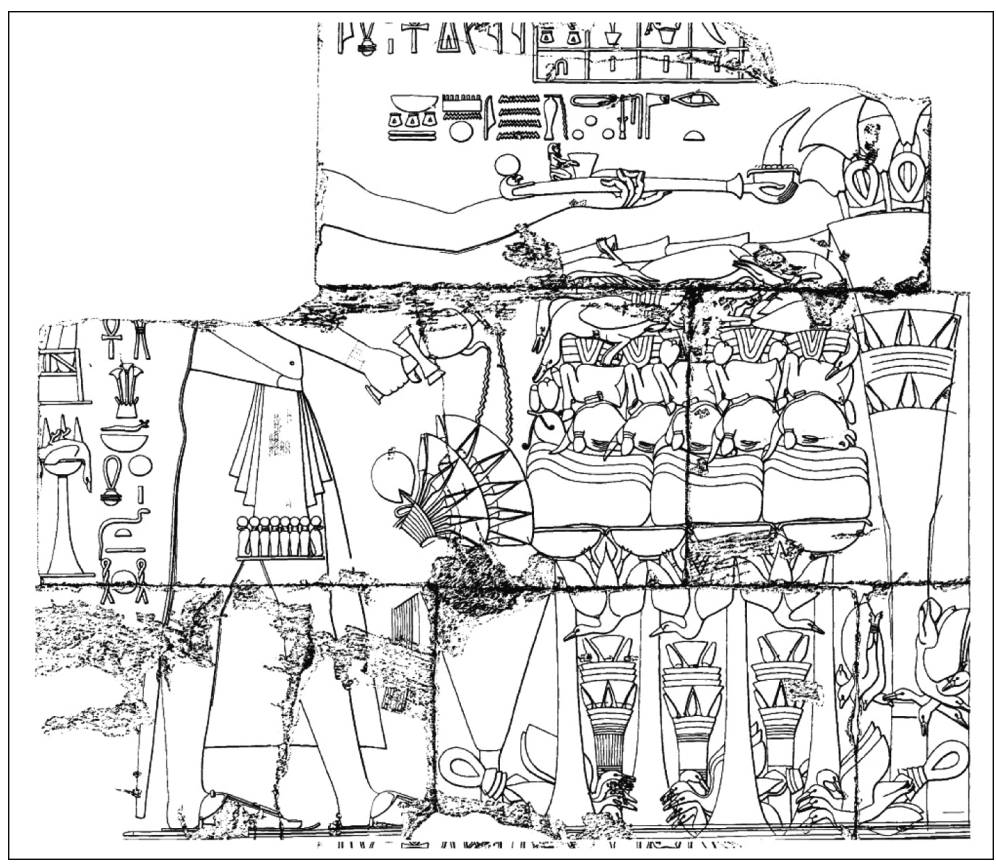

Fig.1. Rei vertendo libações e queimando incenso diante de uma mesa de oferendas posicionada à frente da barca processional divina (Epigraphic Survey 1994: pr .5).

Fig.2. Relevo de Tutankhamun usurpado por Horemheb no templo de Luxor. Foto do autor.

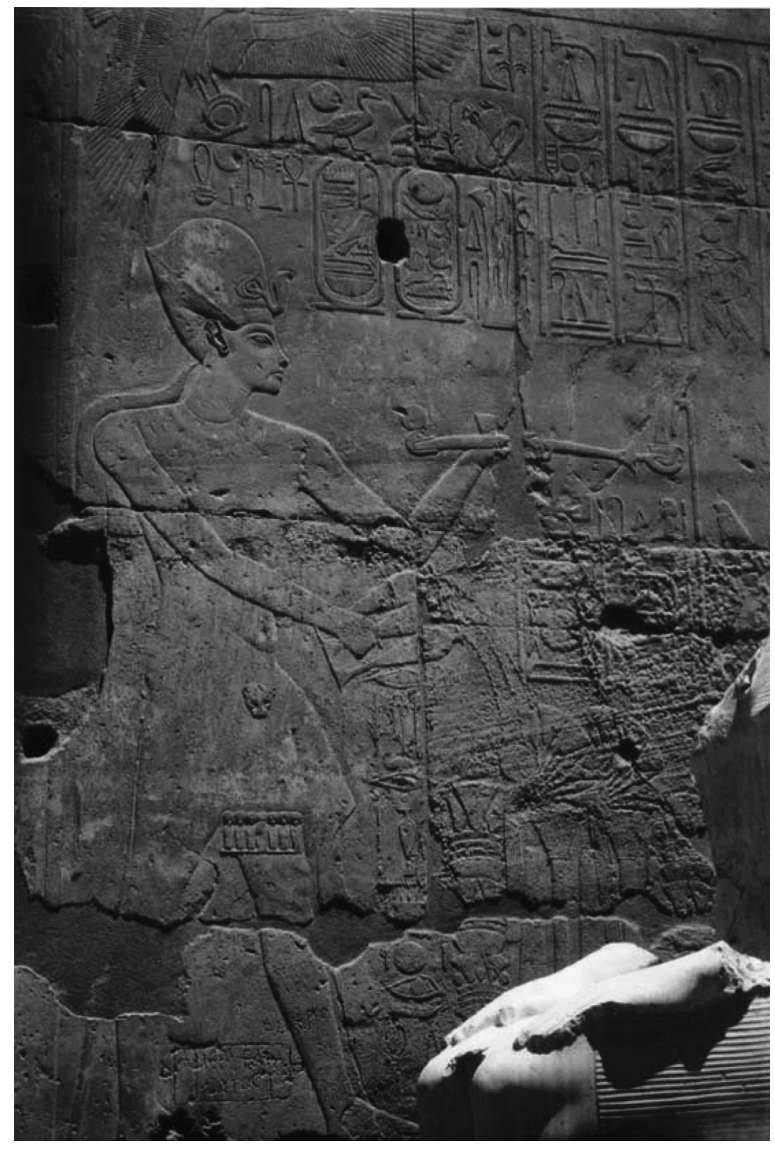




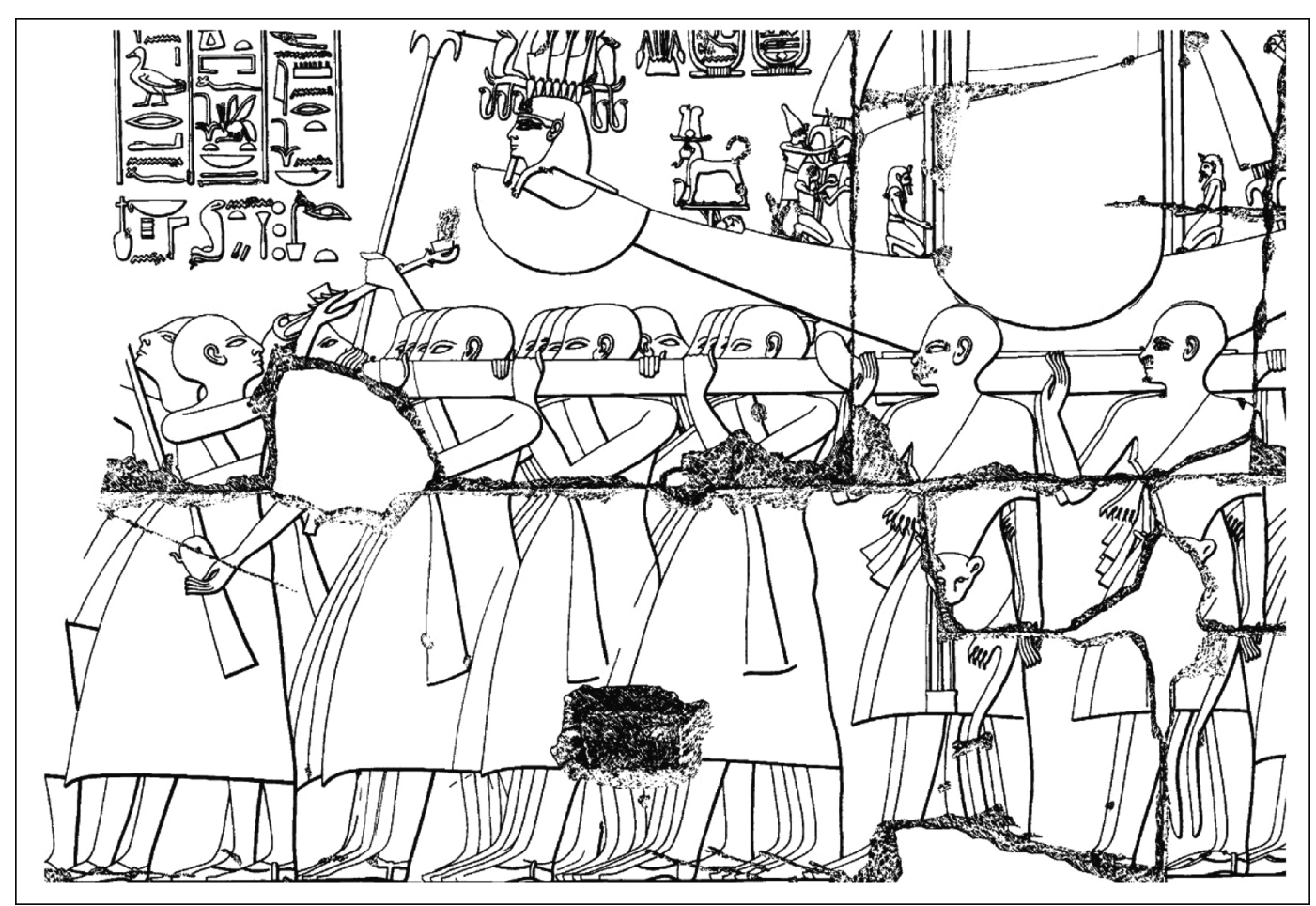

Fig.3. Cena da barca do rei sendo transportada do templo de Karnak por ocasião da festa de Opet (Epigraphic Survey 1994: pr. 16).

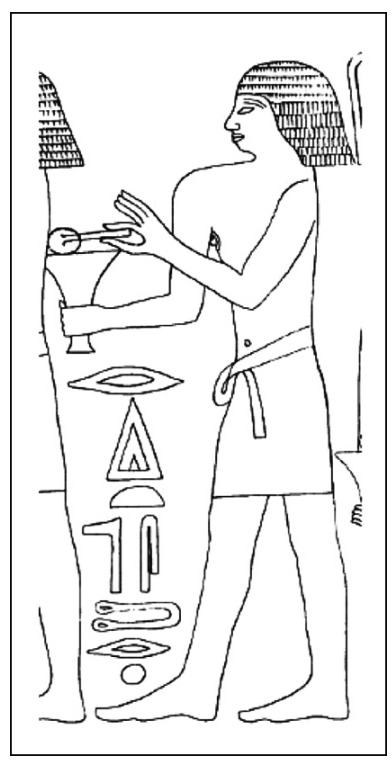

Fig. 4. Cena da mastaba de Qar e Idu (Simpson 1975: fig. 25).

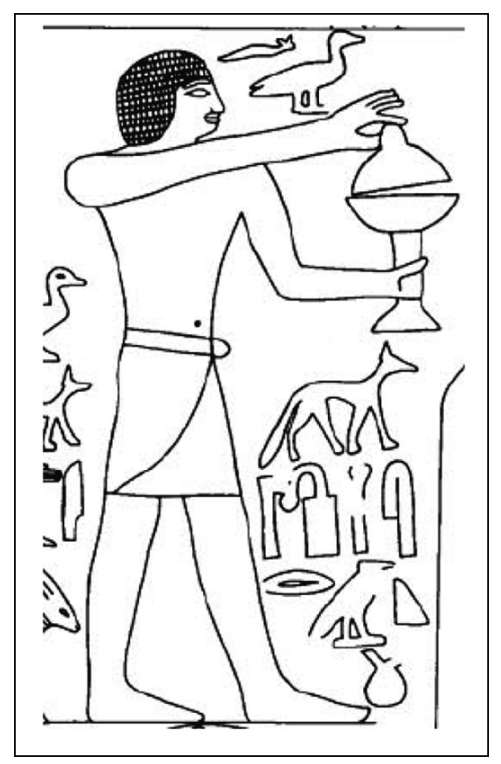

Fig. 5. Cena da mastaba de Qar e Idu (Simpson 1975: fig. 39).

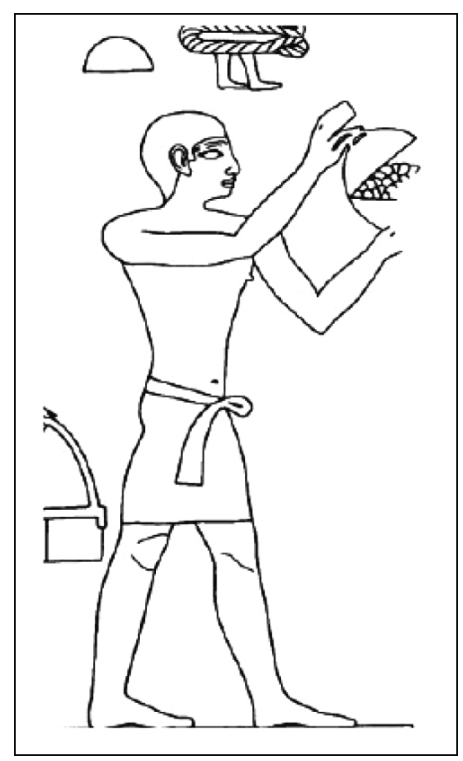

Fig. 6. Cena da mastaba de Khafkhufu, Giza (Simpson 1978: fig. 33). 


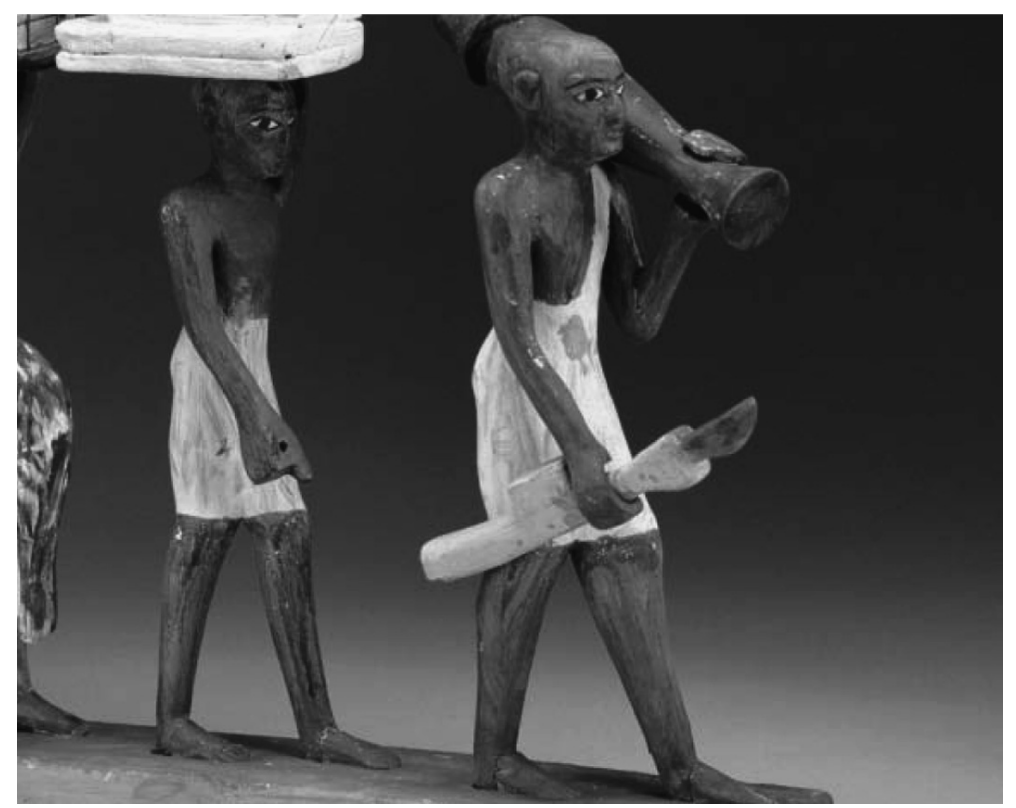

Fig. 7. Oficiante de uma das maquetes de Meketre, reinado de Amenemhat I MMA 20.3.8.
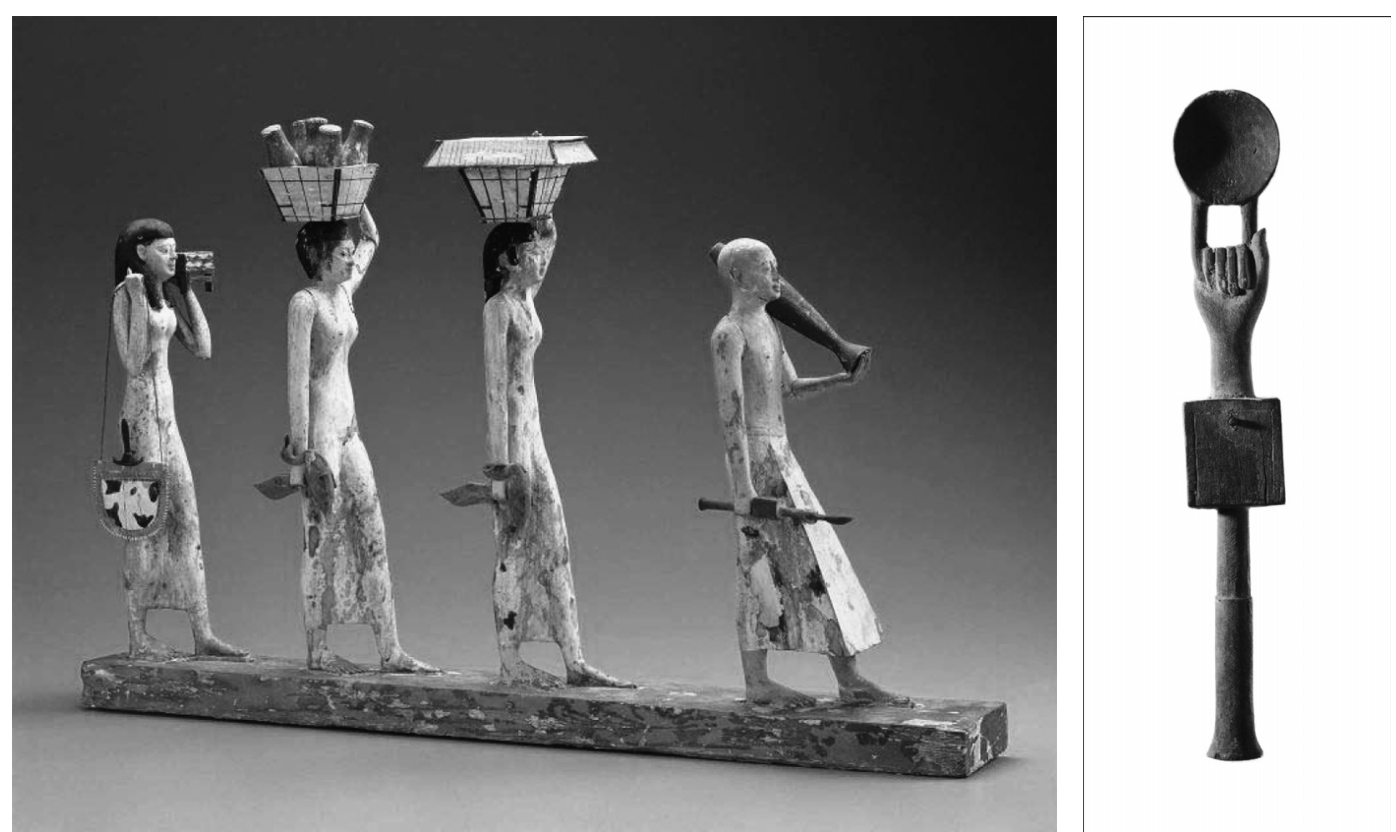

Figs. 8-9. Incensário do modelo de Djehutynakht, final de $11^{\text {a }}$ din início da $12^{\text {a }}$ Deir el Bersha, $11.1 \mathrm{~cm}$ compr. Boston MFA 20.1124. 

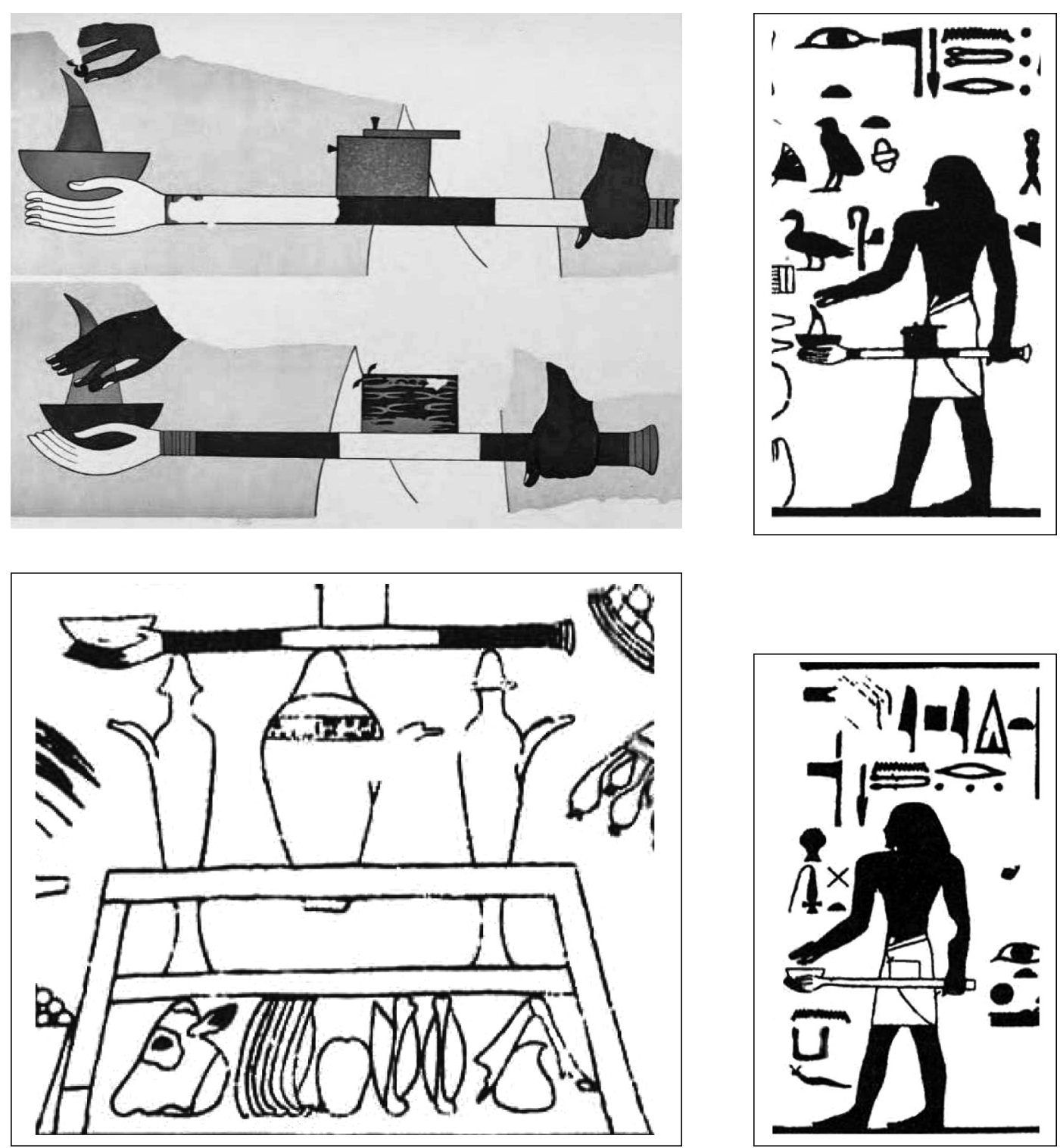

Figs. 10-13. Beni Hassan, tumba de Amenemhat (n²). (Newberry 1893: prs. XVII, XVIII; 1900: pr. XVII) 
Fig. 14. Beni Hassan, tumba n³. (Newberry 1893: pr. XXXV).

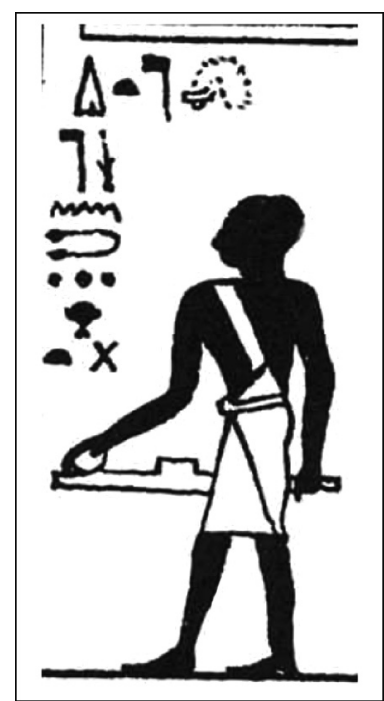

Fig. 15. Livro dos mortos de Hunefer, 19a din., Museu Britânico. Notar a diferença entre os incensários que o sacerdote carrega e aqueles que estão sobre a mesa de oferendas à frente dele. British Museum Registration number 1852,0525.1.5, BM Big number 9901,5. (C) The Trustees of the British Museum (Quirke, Spencer 1997: p149).

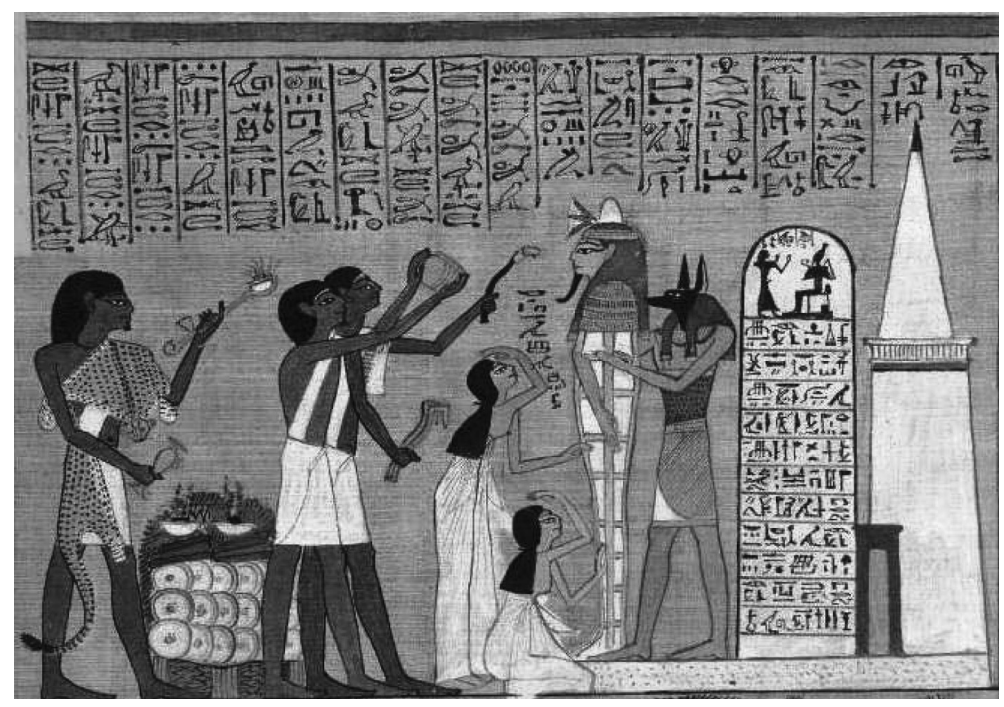

Fig. 16. Incensário de braço de metal representado na tumba de Puimrê (Norman de Garis Davies, The tomb of Puyemrê at Thebes, V. 1, 1922: prancha XXVc).

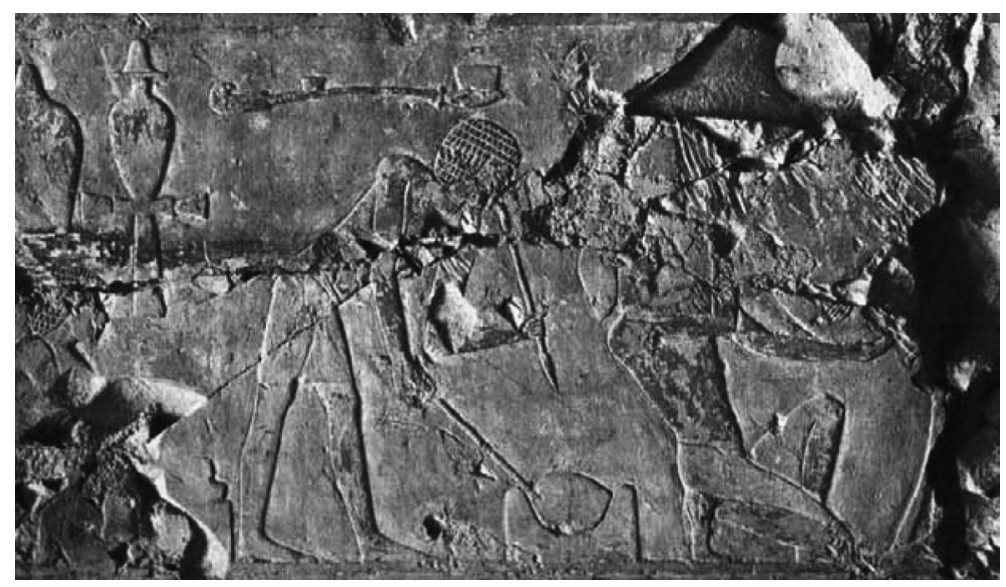




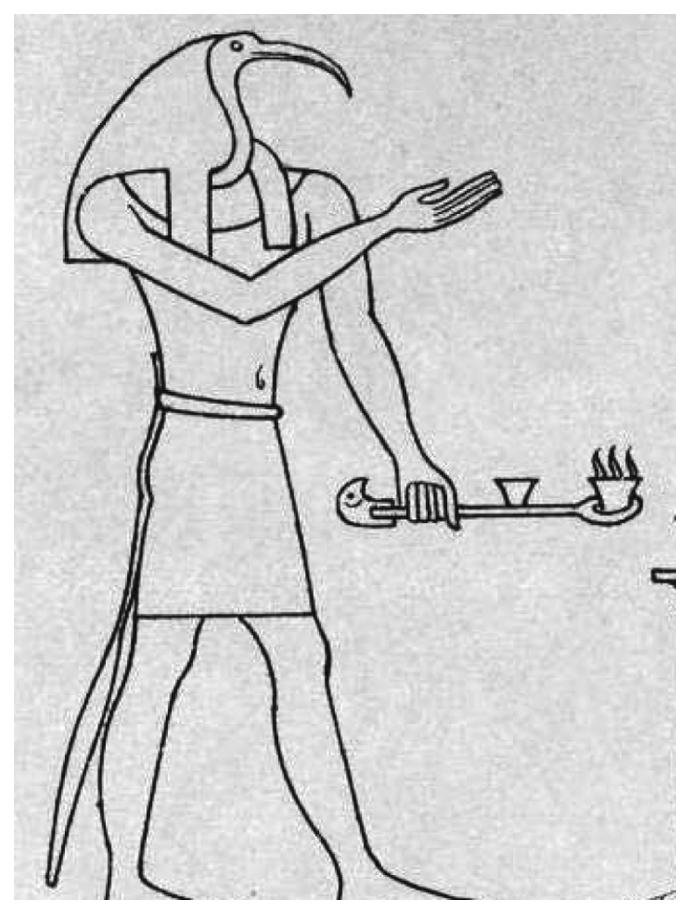

Fig. 17. Detalhe da cena de Thot diante de Ramsés II (Mariette 1869: pr. 24a).

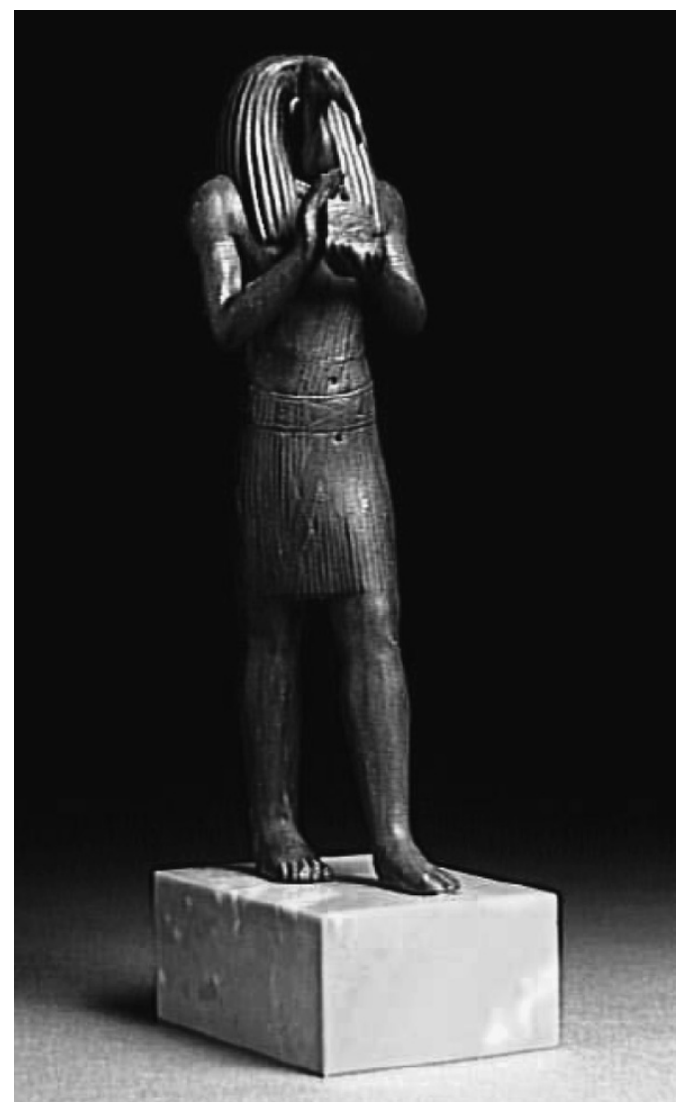

Fig. 18. Thot ofertando o wedjat, Per. Tardio, bronze. Louvre E 3803.

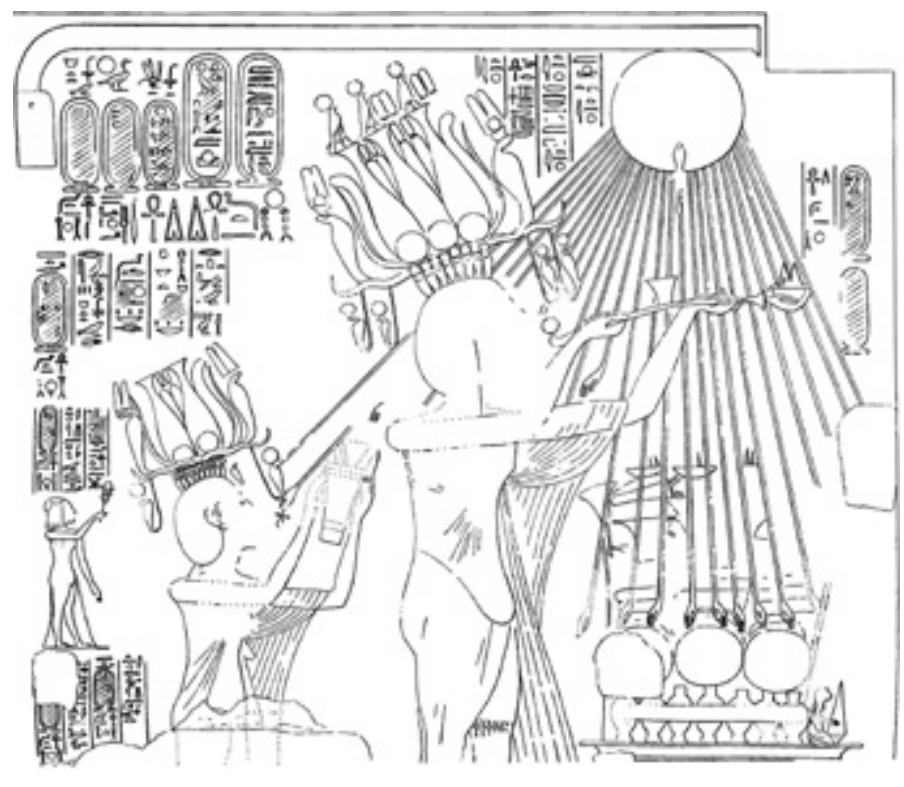

Fig. 19. Akhenaton, túmulo de Penehesy (Davies 1905, Vol II, pr. VIII). 


\section{Referências bibliográficas}

ASSMANN, J.

2009 Egyptian solar religion in the New Kingdom: Re, Amun and the crisis of politheism. Nova York: Routledge.

BADAWY, A.

1976 The tombs of Iteti, Sekhem'ankh.Ptah, and Khaemnofert at Giza. Berkeley: University of California Press.

BONNAMY, Y.; SADEK, A.

2010 Dictionnaire de hiéroglyphes. Arles: Actes Sud.

BURGOS, F.; LARCHÉ, F.

2006 La chapelle Rouge, le sanctuaire de barque d'Hatshepsout, v. 1, facsimilés et photographies des scènes. Paris: Éditions Recherche sur les Civilisations.

CALVERLEY, A.M.; BROOME, M.F.

1935 The temple of king Sethos I at Abydos, vol. II: The chapels of Amen-Rê', Rê'-'Harakhti, Ptah, and king Sethos. Londres/Chicago: Egypt Exploration Society/ The University of Chicago Press.

CAMINOS, R.A.

1998 Semna-Kumma II, The Temple of Kumma. Londres: Egypt Exploration Society.

CORTEGIANNI, J.P.

2007 L'Égypte ancienne et ses dieux. Paris: Fayard.

DAVIES, N.G.

1905 The rock tombs of El Amarna, vol. II: The tombs of Panehesy and Maryra II. Londres: Egypt Exploration Fund.

1922-1923 The tomb of Puyemrê at Thebes, 2 vols. Nova York: The Metropolitan Museum of Art.

DESROCHES-NOBLECOURT, C.

1997 Amours et fureurs de La Lointaine. Clés pour la compréhension des symboles égyptiens. S.l. :Stock/Pernoud.

EPIGRAPHIC SURVEY

1994 The festival procession of Opet in the colonnade hall, with translations of texts commentary and glossary. Oriental Institute Publications vol. 112. Chicago: The Oriental Institute of the University of Chicago.

1998 Reliefs and inscriptions at the Luxor Temple, vol. 2. The facade, portals, upper register scenes, columns, marginalia and statuary in the colonnade hall with translations of texts, commentary, and glossary. Oriental Institute Publications vol. 116. Chicago: The Oriental ÉTIENNE, M Institute of the University of Chicago.

1999 Amenhotep IV censing an altar. In: Freed, R.E.; Markowitz, Y.J.; D’Auria, S.H.
(Eds.) Pharaohs of the Sun: Akhenaten, Nefertiti, Tuthankhamen. Boston: Museum of Fine Arts: p. 207, n²1.

ÉTIENNE, M. (Dir.)

2009 Les portes $d u$ ciel. Visions $d u$ monde dans l'Égypte ancienne. Paris: Musée du Louvre éditions/Somogy.

FAULKNER, R.O.

1996 A concisise dictionary of middle Egyptian. Oxford: Griffith Institute.

FERRARI, D.

1998 Gli amuleti dell'antico Egitto. Imola: La Mandragora.

FREED, R.E.; BERMAN, L.M.; DOXEY, D.M.; PICARDO, N.S. (Eds.)

2009 The secrets of tomb 10A, Egypt 2000 BC. Boston: Museum of Fine Arts, Boston, Publications.

GARDINER, A.

1969 Egyptian grammar being an introduction to the study of hieroglyphs. Oxford: Griffith Institute/Oxford University Press.

GIORGINI, M.S.

1998 Soleb V, le temple. Basreliefs et inscriptions. Cairo: Institut Français d'Archéologie Orientale.

GOYON, J.C.

1984 Räucherung. In: Helck, W.; Otto, E. (Eds.) Lexikon der Ägyptologie, Band V. Wiesbaden, Otto Harrassowitz: 83-86.

1997 Rituels funéraires de l'Ancienne Égypte. Paris: Les Éditions du Cerf.

HANNIG, R.

2006 Großes Handwörterbuch Ägyptisch-Deutsch (2800-950 v. Chr.) - Marburger Edition. Mainz am Rhein: Philipp von Zabern.

HAYES, W.C.

1959 The scepter of Egypt. A background for the study of the Egyptian antiquities in The Metropolitan Museum of Art, Part II: The Hyksos Period and the New Kingdom (1675. 1080 B.C.). Cambridge (Massachusetts): Harvard University Press.

HORNUNG, E.; ABT, T.

2007 The Egyptian Amduat, The book of the hidden chamber. Zurique: Living Human Heritage Publications.

INCONNU-BOCQUILLON, D.

2001 Le mythe de la Déesse Lointaine à Philae. BdE 132. Cairo: Institut Français d'Archéologie Orientale.

KAPER, O.E.

2003 The Egyptian god Tutu; a study of the sphynx- 
god and master of demons with a corpus of monuments. OLA 119. Leuven: Peeters.

LEBLANC, C.; SILIOTTI, A.

1997 Nefertari e la Valle delle Regine. Firenze: Giunti.

MARIETTE, A.

1869 Abydos, Description des fouilles exécutées sur l'emplacement de cette ville. Tome I: Ville antique. - Temple de Séti. (Appendice A).

MORET, A. Paris: Franck.

2007 Le rituel du culte divin journalier en Égypte d'après les papyrus de Berlin et les textes $d u$ temple de Séti Ier, à Abydos. Geneva: Slatkine Reprints.

MÜLLER, M.

2001 Re and Re-Horakhty. In: Redford, D.B. (Ed.) The Oxford Encyclopedia of Ancient Egypt, v. 3. Nova York, Oxford University Press: 123-126.

MURRAY, M.A.

1905 Saqqara mastabas, part I. Londres: Bernard Quaritch.

NEWBERRY, P.

1893 Beni Hasan, v. I. Londres: Egypt Exploration Fund.

1900 Beni Hasan, v. IV. Londres: Egypt Exploration Fund.

QUIRKE, S.; SPENCER, J.

1997 The British Museum book of ancient Egypt. Londres: British Museum Press.

REDFORD, D.B.

1999 The beginning of the heresy. In: Freed, R.E.; Markowitz, Y.J.; D'Auria, S.H.

(Eds.) Pharaohs of the Sun: Akhenaten, Nefertiti, Tuthankhamen. Boston, Museum

REEVES, N. of Fine Arts: 50-59.

1999 The royal family. In: Freed, R.E.; Markowitz,
Y.J.; D'Auria, S.H. (Eds.) Pharaohs of the Sun: Akhenaten, Nefertiti, Tuthankhamen. Boston, Museum of Fine Arts: 80-95.

ROBINS ,G.

1997 The art of ancient Egypt. Londres: British Museum Press.

SILIOTTI, A.

2006 La Vallée des Rois, guide des meilleurs sites. Paris: Gründ.

SIMPSON, W.K.

1975 The mastabas of Q ar and Idu, G7101 and 7102. Boston: Museum of Fine Arts, Boston.

1978 The mastabas of Kawab, Khafkhufu I and II. Boston: Museum of Fine Arts, Boston.

TERRACE, E.L.B.

1969 Egyptian paintings of the Middle Kingdom. The tomb of Diehuty-nekht. Nova York: George Braziller.

VANDIER, J.

1964 Manuel d'archéologie égyptienne, Tome IV, bas-reliefs et peintures, scènes de la vie quotidienne. Paris: Éditions A. et J. Picard.

WEEKS, K.

2005 The treasures of Luxor and the Valley of the Kings. Vercelli (Italia): White Star.

WILKINSON, R.H.

1996 Reading Egyptian art. A hieroglyphic guide to ancient Egyptian painting and sculpture. Londres: Thames and Hudson.

WINLOCK, H.E.

1955 Models of daily life in ancient Egypt from the tomb of Meket-Rç' at Thebes. Cambridge (Mass.): The Metropolitan Museum of Art/Harvard University Press.

ZIEGLER, C.

1993 Le mastaba d'Akhethetep, une chapelle funéraire de l'Ancien Empire. Paris: Réunion des Musées Nationaux. 